\title{
The Rabha and Their Social Movement (1925-1950): A Case Study of North Bengal
}

\author{
Prof. Bipul Mandal ${ }^{1,}$ Prof. Manadeb Roy ${ }^{2}$ \\ ${ }^{1,}$ Assisstant Professor \\ Department of History \\ Kaliyaganj Colege \\ University of Gour Banga \\ 2,Assistant Professor \\ Department of History \\ Khandra College \\ University of Burdawan
}

\begin{abstract}
The paper will attempt to look into the significant characteristics of the Rabha society and their social movement in North Bengal. It may be mentioned that a growing interest in recent times is discernible among a number of scholar, historian for writing history about Rabha tribes. Rabha is a little known ,scheduled tribe community of West Bengal,Assam and Megalaya. The language /dialect spoken by the Rabha people is also the same name. In West Bengal, Rabha people mainly live in Jalpaiguri district and Cooch Beher district. Moreover almost 70 percent of them live Jalpaiguri. In Assam, the Rabha live mostly in Goalpara and Kamrup district.The whole area of Eastern and Western Dooars ,may be termed as the cradle land of the Rabhas. The Rabhas belong to the Indo-mongoloid group of people and have similarities with other members of Bodo group such as Garos, kachari, mech, hajong and others. The traditional economy of the Rabhas in general is based on agriculture, forest based activities and weaving. In the past, the Rabhas used to practice shifting cultivation. The Rabha society was matriarchal. By birth they used to obtain the 'gotra' of their mother. The Rabha Community previously believed in animism. But now they are intermingled with Hinduism. In the first half of the $20^{\text {th }}$ century the movement started among the Rabhas in North Bengal for upgrading their position 'to get equal social rank as that of the Hindu caste like the Rajbansis. The act of negligence created resentment among the Rabhas. Actually the Rabha community is politically and socioeconomically suppressed and is perhaps considered to be the most backward tribal group in North Bengal as well as North-East India lacking proper socio-economic development as well as proper representation and so on, which requires very sympathetic attention in the existing sociopolitical set up.
\end{abstract}

Keywords: Enlightened, Kshatriyaisation, Mobilisation, Phonological levels, Listi Rabha Ronkho

\section{Introduction}

The Rabhas belong to the Indo-mongoloid group of people and have similarities with other members of Bodo group such as Garos, kachari, mech, hajong and others. The Rabhas are one of the indigenous tribes of Assam. Their concentration is found throughout the state of Assam. Besides its adjoing state like West Bengal, Meghalaya and a few areas of Bangladesh. As per 1991 census report of Assam are influenced by different cultural and linguistic communities to a large extent. As a result of adoption of culture and linguistic elements from other communities and repudiation of their own identity. Some of the clan groups of the rabhas have shifted to the Hindu Asomiya caste to a great extant. However, some of them are in the process of mobilisation to survive and preserve their inherent culture and language. Edward Tuite Dalton also noticed "The Rabhas and the Hajongs of the Goalpara district are also branches of the Kachari race and connected with the Garo."

In North Bengal the Rabhas are the inhabitants of Duars region extending the river Teesta to Sarnakosh (Sankosh). The Rabhas are generally of two types - regional and ethnic.

E. Dalton's view is that the Rabhas are divides to Rangdania and Pati. In North Bengal Rabha people mainly live in jalpaiguri and Cooch Behar District.

A. playfair (1909) also has pointed out some linguistic and cultural similarities between the Rabhas and Garos. The Rabhas of West Bengal and Assam generally speak the local Bengali and Assamese dialects. The Rabhas who live in the forest village have retained their original Rabha dialect to a great extent.

There is no doubt that about the fact that the Rabhas have a language and culture to identify them as a distinct tribe.There is no logic to offer a vague opinion that a Kachri becomes 
a Rabha through the acceptance of Hinduism or proselytism or that the rabhas are an off-shoot of the Garos. Among the scholars there are diversified opinions and explanations about the origins of the Rabhas. However,ethnic affinities establish them to be member of the great Mongolian stock. ${ }^{3}$ The Rabha have some clan groups which consist of Rongadani, Maitori, Koch (Pani coch ),Hana, Pati, Dahuri, Totla,Bitalia etc. The first three groups are the major socio-linguistic group. They are maintaining their inherent language and culture in comparison to the other minor groups .

The group of the Rabhas i, e, Rongadani, Maitori and Kosh show some variation in the Lexical and phonological levels. The Rangdani claim for them a position of superiority.

The traditional economy of the Rabhas in general is based on agriculture, forest based activities and weaving. In the past, the Rabhas used to practice shifting cultivation. They continued to cultivate the with 'Gogo or bill-hook'. Later they took up the job of settled cultivations and started cultivations with plough. Besides cultivations, hunting was also an old practice of Rabha people weaving was a traditional occupation of the Rabha women.

The Rabhas living at Jalpaiguri and Cooch Behar have been greatly influenced by the Rajbansi culture as they are surrounded by the Rajbansis. As the Rajbansis enjoyed superior status in the social sphere of North Bengl. Naturally the Rabhas tried to elevate their social dignity.

The Rabha society was matriarchal. By birth they used to obtain the 'gotra' of their mother. Even after marriage the groom ge nerally use to go to house of their in laws. The Rabha girls inherited the right of property and enjoyed it. But now the system is longer in existence. The Rabha Community previously believed in animism. But now they are intermingled with Hinduism.

The Christian Missionaries preached the gospel of Jesus Christ among the Garoes, Meches, Nagas and a good number of Meches embraced Christianity. Under this circumstances the leaders of Jalpaiguri Hindu Mahasabha took initiative to keep the Christian missionaries away from the Rabha society. There was an apprehension that like to the Meches the Rabhas would be converted into Christianity. So the leaders of Hindu Mahasabha helped them to come under the fold of Hinduism.

\section{Emergence of the Rabha written literature:}

Rabha has a rich tradition in respect to the folk-literture. Among the Rabhas, songs of the folk, tales, legends, chamars related to various religious festivals and performances, various myths, idoms, and proverbial sayings are still prevailing as relic of the folk knowedge.

While consider the written movement of Rabha literature, it is necessary to notice the beginning of 1900 A.D. The written tradition of rabha literature was started towards the beginning of twentieth century with the publication of religious book 'Markani Nima Saikai' (1909) which was translated into Rongadani dialect from the Gospel of Mark of the original holy Bible. It was most probably the oldest specimen of written trend in Rabha. Penam Lamon Dam'(a religious book) was written by Purna Chandra Kosh in Rabha in 1926. Besides some pioneer works were done by Rajen Rongkho and Adhar Bantho. 'Rabha Zibraw Orgi'(a book of Rabha language) and 'Bhag Tekkang' (1948) were written by Rajen Rongkho and published by Ishwar Chandra Hato. Thus Adhar Bantho wrote a book 'Rabha Bhasa'(1950).

During this period Various socio-cultural organisation came into existence. For example, 'Rabha Krishti Sanmilan'(1955) had taken up many effective plans for the development of the Rabhas. Late Rajen Pam and Rajen Rabha both were the pioneer in this respect. Prasanna Kumar Pam wrote a legendary drama 'Dodan Bir'(1957) which was most probably the fiast drama in Rabha.Thus several outstading Rabha dramas on socio-cultural aspects were flourishing very slowly.

In 1973 the first Rabha magazine 'Zatini Khurang'(massage of the race) was published under the editorship of Prakash Rabha. In this decade, an outstanding magazine 'Champai'(1978, honeycomb) was published under the editorship of Listi Rabha Ronkho.

\section{Social Movement}

The social reform movement of the Rabhas was started in two phases. The movement of the first phase began in 1930. The background of the movement of 1930 was the exclusion of the Rabha people from the Harisabha of Bharoa village. It is a village of Tugangunj subdivision of Cooch Behar. Religious gatherings were origanised in this Harisabha by the non-Rabha Hindus. The Rabhas were not allowed to enter into the Harisabha. 
This act of negligence created resentament among the Rabhas. Bhabendra Narayan Chowdhury, a saint became very much hurt and expressed the view that Rabhas were of Hindus and they had the right to perform every hindu ritual. The then hakim of Tufangunj Manabendra Thakur also helped in the movement of the Rabhas. In 1934, Bhabendra Narayan Chowdhury initiated in the purification of the Rabhas. After sometimes the Rabha leaders unitedly adopted some decisions viz that henceforth Rabhas be considered as Sudra, they would retrain themselves from drinking etc.

The Rahas were much influenced by the Kshatriyaisation of the Rajbansis during the early forty's of the twentieth century and they also started a movement for upgrading their position 'to get equal social rank as that of the Hindu caste like the Rajbansis'. To obtain the higher social position they would give up rearing of pig and fowl willingly. They would also give up their Rabha title and use 'Das', it was also decided.

For the purification the Rabha people assembled at premises of a primary school in Bharoa village. More than hundred Rabhas participated there. Some Rajbansi were also present. As a result of this purification the Rabhas resisted themselves from rearing of pigs and fowls. It had on adverse effect on the economic status of the Rajbansis. The Rajbansis actually deployed the Rabhas for rearing the pigs and fowls. As the Rabhas gave up it. The Rajbansis suffered economic hardship. They began to pressurise the Rabhas to go back to their previous religion and within two years most of the Rabhas returned back to their previous life.

The Rabhas faced several problems even after elevating themselves to the rank of Hindus. Some primitive Rabha people of Barasalbari and Kamakkhaguri though were numerically superior refused to accept the newly converted Hindu Rabha in their society. Moreover the Rajbansis also did not consider them as Hindu. Caste-Hindus also refused to drink water touched by a Rabha. So in the Rabha society their traditional rituals and customs were reintroduced and their movement came to a halt temporarily.

In the second phase the movement started in 1940. A teacher of Bhatibari village of Alipurduar named Dhaneswar Bhattacharjee initiative to convert them to Hinduism. At that time Christian Missionaries guided by pro stylizing zeal tried to convert the Rabhas. Shri Bhattacharjee realised it well that if the Rabhas were not be brought within the banner of Hinduism they would surely Christian like the Meches of Khoardanga, Mahakaguri village. Shri Bhattacherjee met with the Pandit Madan Kumar Smritiratna of the Cooch Behar royal family. He opined that the Rabhas might be considered as Hindus but to attain Hinduism they had to expiate. The Rabha accepted Shri Dhaneswar Bhattacherjee as their 'guru'. He organised 'jognja' in different places for the purification of the Rabhas. A good number of Rabhas of Bara Salbari, Bondejels village of Tufangunj subdivision of Cooch Behar and also from Madhyamansi, Daldali, Hemaguri regions of Alipurdur thana of Jalpaiguri district became Hindu through expiation. The leaders of their movement were German Rabha, Rajbar Rabha, Baburam Rabha, Hanuram Rabha, Bholanath Rabha etc. Dhaneswar Bhattacherjee also invited two brahmanas named Hridinath Deb Sharma and Mohit Kumar Deb Sharma and two barbars named Ghanashyam Seal and Nidhiram Seal from Assam to perform different social and religious rituals of the Rabhas.

Now the Rabhas of Cooch Behar and Jalpaiguri use the title 'Das'. To mingle with the Hindus they had even accepted their position as a Shudra.

Becoming Hindu the Rabhas of Baro Salbari formed of Hindu Sabha and formulated some policies of action.

(i) They would collect weekly a handful of rice or other cereals given in charity.

(ii) They would sing in praise of Hari weekly.

(iii) They would perform the rituals of the Hindus.

(iv) Development of the society.

(v) Abandonment of chokote (country liquor)

It is known that some prosperous Rajbansis were not satisfied with the elevation of the Rabhas to Hinduism. So they abandoned Dhaneswar Bhattacherjee. In 1957 the Rajbansis inspired the Rabhas to embrace Kshatriya and assured them to accept them as kshatriya.

The Rabhas of forest area were not enlightened with their reform movement. The lack of communication was the main hindrance on their way to sanskritization. On the advent of a saint from Darjeeling named Dharmaraj, created a tremendous sensation and brought a magic change on the outlook of the Rabhas dwelling at remote forest areas. His spiritual name was Tribouddha Jnandhari Janayogi and the name of the religion was Janayogi Prakriti Raj Dharma. An Ashram known as Janayogi ashram was established in western Duras in 1958. The main object of this 
religion was to worship five elements like Moon, Sun, Soil, Water and air. These five elements were called "Pancha Chakraborty". The religion emphasised on emancipation from family bondage, scientific agricultural production, dowry free marriage, simple living and mutual understanding and socialistic view.

Rabhas of North Bengal also participated in the Indian struggle for independence. They played a pivotal period in quit India movement. In 1942, the whole India was tremendously moved by the Quit India Movement. Kumargram, a remote village of North Bengal was influenced by this movement Debendra Nath Das participated in the movement braving all social hardels. Under his leadership Rabha community of Alipurduar subdivision took part in the Quit India movement. For preaching nationalistic principles Deben Das was ousted from his own soil Cooch Behar and gradually Kamakkhaguri village of Jalpaiguri district became the life centre of Quit India movement in North Bengal. Selfless devotion of Deben Das towards his country helped him to reach to the zenith of popularity among the tribal people especially among the Rabhs. In 1942, September, in a meeting, decision was taken to make Quit India movement a mass movement in kumargram.

\section{Conclusion}

I conclude with the observation that the Rabha community is politically and socioeconomically suppressed and is perhaps considered to be the most backward tribal group in North Bengal as well as North-East India lacking proper socio-economic development as well as proper representation and so on, which requires very sympathetic attention in the existing sociopolitical set up.

In the recent years Rabhas have gained education through missionaries but have probably moved away from their indigenous culture and beliefs.

But in some pockets of North Bengal Rabhas are still trying to preserve their traditional ways of life. It is a struggle to maintain the age-old practices of their forefathers without turning away from the fruits of modernity. Only time can reveal the outcome of this social metamorphosis taking place in the tribal heartland of North Bengal.

\section{References :}

[1]. Phukana Chandra Basumatar ,, The Rabha Tribe of North-East India, Bengal and Bangladesh ( Mittal Publication, Delhi,2010)

[2]. Sukhabilas Barma, Socio-Political Movements in North Bengal (Global Vision Publishing House,Delhi,2007)

[3]. Amal Kumar Das, M.K Raha, The Rabhas of West Bengal( Calcutta, SC \& ST Welfare Dept. Govt. of West Bengal, 1989)

[4]. Ranajit Dasgupta, Economy, Society and Politics in Bengal :Jalpaiguri’, 1869

[5]. Saumitra Ghosh, Vanbasi Rabhara (in Bengali) Desh, Vol-57 (12), 1990

[6]. Pabit Kumar Gupta, Uttar Banger Rabha Samaj O Dharma Sanskar Andolon , (in Bengali) in Madhuparni, Special North Bengal Issue, 1977

[7]. K. Mishra, Amrita Dutta, Exploring the Conditions of Tribal People and their Culture in West Bengal( Rachayita, Kolkata, 2012)

[8]. M.K Raha, Matrilny to Patriliny : A Study of the Rabha Society ( Gyan Publishing House, Delhi, 1989)

[9]. B. Roy Choudhury, Social Mobility Movement Among the Rabhas of North Bengal( Manin India, Vol. 50 (1), 1970)

[10]. Rebatimohon Saha, 'Jalpaiguri Jelar Koch Rabha Samaj' (in Bengali) Madhuparni (ed.) Special issue on Jalpaiguri District

[11]. Pal, Sunil, “Adibasi Rabhader Sanskar Ande-lene’ (in Bengali), Uttar Banga Samad, Siliguri, 10.11.1990

[12]. Interviews i) Niren Rabha - Bochamari, Tufanganj, Cooch Behar

[13]. Guided by- Dr. Pam Khan Pau, Superviser and Assistant Professor, Department Of History, Visva-Bharati University, Shantiniketan,Bhirbhum, West Bengal

[14]. Gazetters of West Bengal Government
i) District of Cooch Behar
ii) District of Jalpaiguri
iii) District of Darjeeling 